\title{
sciendo
}

\section{Temporal characterization of the insulin resistance during puberty in mice}

\author{
Pryscila D.S. Teixeir A*, Mariana R. Tavares*, Jose Donato Jr. \\ Universidade de Sao Paulo, Instituto de Ciencias Biomedicas, Departamento de Fisiologia e Biofisica, Sao Paulo, Brazil \\ E-mail:jdonato@icb.usp.br
}

Objectives. The onset of puberty in humans is followed by an increase in insulin resistance and this transient phenomenon decreases at the end of the puberty. However, the insulin resistance during puberty has not been described in mice. Thus, in the present study we performed a temporal characterization of the development of insulin resistance during puberty in male and female C57BL/6 mice.

Methods. From the fourth week of life male $(n=18)$ and female $(n=32)$ C57BL/6 wild-type mice were weekly subjected to insulin tolerance tests until the seventh week of life. Blood glucose levels were determined using a glucose meter through samples collected from the tail tip. Vaginal opening was assessed daily in female mice. Preputial separation was determined in a subgroup of males.

Results. We observed a transient increase in the area under the curve of the insulin tolerance tests and in basal glycemia in female mice at the time of vaginal opening (between the fourth and fifth week of life) compared with previous and subsequent weeks of pubertal development. In contrast, male mice show no changes in insulin sensitivity during puberty.

Conclusions. Our findings demonstrate that the insulin resistance at puberty can also be observed in female mice and this peak occurs at the time of vaginal opening. Our temporal characterization can be used as a reference for future studies that aim to study glucose homeostasis during puberty in rodents.

Key words: insulin resistance, puberty, mice

Puberty is characterized by numerous physiological, physical, metabolic, and endocrine changes that ultimately lead to the development of reproductive capacity. During the transition from prepubertal stages to adulthood, there are temporary increases in the secretion of sexual steroids, growth hormone $(\mathrm{GH})$, and insulin-like growth factor-1 (IGF-1). These endocrine changes not only induce the physical and reproductive alterations typical of this development stage, but they also cause metabolic consequences (Veldhuis et al. 2006). Noteworthy, classical studies reported a transient insulin resistance during puberty, causing poor glycemic control in both diabetic and normal adolescents (Amiel et al. 1986; Bloch et al. 1987; Moran et al. 1999). Increased GH levels are known to cause insulin resistance (Rizza et al. 1982). IGF-1 levels, which change according to $\mathrm{GH}$ secretion, are correlated with insulin resistance during puberty, indicating that GH/IGF-1 axis is an important contributor of the insulin resistance observed during puberty (Moran et al. 2002).

Although the insulin resistance during puberty has been well-documented in humans (Amiel et al. 1986; Bloch et al. 1987; Moran et al. 1999, 2002), to our best knowledge this phenomenon has not been described in experimental animals. Considering the

Corresponding author: Jose Donato Jr., PhD., Av. Prof. Lineu Prestes, 1524, Sao Paulo, SP, Brazil, 05508-000; phone: +55-11-30910929; fax: +55-11-3091-7285; e-mail: jdonato@icb.usp.br. *These authors contributed equally to this study as co-first authors. 
importance of studies with rodents for the detailed understanding of physiological mechanisms, it is imperative to determine whether changes in glucose homeostasis during puberty occur in a similar way to humans. Therefore, the objective of the present study was to perform a temporal characterization of the development of insulin resistance during puberty in male and female C57BL/6 mice.

\section{Material and methods}

Animals. C57BL/6 wild-type mice were produced and maintained in standard conditions of light $(12 \mathrm{~h}$ light/dark cycle) and temperature $\left(22 \pm 1^{\circ} \mathrm{C}\right)$. Mice received a regular rodent chow diet and filtered water ad libitum, unless specified. The experiments were previously approved by the Ethics Committee on the Use of Animals of the Institute of Biomedical Sciences, University of São Paulo (protocol number: 73/2017).

Experimental design. Mice were weaned at 3 weeks of age, separated according to sex and maintained in cages with 2 or 3 animals. From the fourth week of life, males $(n=18)$ and females $(n=32)$ were weekly subjected to insulin tolerance tests (ITT), until the seventh week of life. Food was removed from cage 4 hours before each test and after evaluation of the basal glucose level (time 0), mice received an intraperitoneal injection of $1 \mathrm{IU}$ insulin/ $\mathrm{kg}$ body weight, followed by serial determinations of glycemia. Blood glucose levels were determined using a glucose meter (One Touch Ultra; Johnson \& Johnson) through samples collected from the tail tip. Vaginal opening (VO) was assessed daily in female mice. Preputial separation (PS) was determined in a subgroup of males $(n=9)$.

Statistical analysis. The GraphPad Prism software (GraphPad, San Diego, CA) was used for the analyses. The area under the curve was calculated for each ITT and the differences in insulin sensitivity and basal glycemia between the weeks of life were determined by one-way ANOVA and Newman-Keuls post-hoc test. Data were expressed as mean \pm standard error of the mean.

\section{Results}

Female mice display increased insulin resistance at the time of vaginal opening. To perform a temporal characterization of the development of insulin resistance during puberty, ITT were weekly performed in mice at prepubertal and pubertal ages (Figure 1). In female mice, VO was used as an indi- cator of the onset of puberty (Nelson et al. 1990; Bohlen et al. 2016). Females presented vaginal opening around the fourth and fifth weeks of life $(4.8 \pm 0.1$ weeks). To standardize the sexual maturation stage, the ITT values at the time of VO ( \pm 2 days) were compared with the previous and subsequent weeks of pubertal development. A statistically significant increase in the area under the curve of the ITT was observed at the time of $\mathrm{VO}$, compared to other weeks $\left(\mathrm{F}_{(4,111)}=4.297, \mathrm{p}=0.0029\right.$; Figures $\left.1 \mathrm{~A}-\mathrm{B}\right)$. Additionally, females showed increased basal glycemia at the time of $\mathrm{VO}\left(\mathrm{F}_{(4,112)}=4.41, \mathrm{p}=0.0024\right.$; Figure $\left.1 \mathrm{C}\right)$. These findings suggest that female mice display a transient insulin resistance at the time of VO.

Male mice show no changes in insulin sensitivity during puberty. PS was used as an indicator of sexual maturation in a subgroup of males $(n=9)$. PS was observed around the fourth week of life (4.2 \pm 0.2 weeks). However, differently than females, no difference in the area under the curve of the ITT was observed along puberty in male mice $\left(\mathrm{F}_{(4,29)}=0.1594\right.$, $\mathrm{p}=0.9571$; Figures $1 \mathrm{D}-\mathrm{E})$. No changes in basal glycemia were also found $\left(\mathrm{F}_{(4,30)}=0.4145, \mathrm{p}=0.7968\right.$; Figure $1 F)$. When the data of all males $(n=18)$ were analyzed together according to the age, no changes in insulin sensitivity $\left(\mathrm{F}_{(3,58)}=0.4114, \mathrm{p}=0.7454\right.$; Figures $1 \mathrm{G}-\mathrm{H})$ or basal glycemia $\left(\mathrm{F}_{(3,58)}=1.249\right.$, $\mathrm{p}=0.3004$; Figure 1I) were observed.

\section{Discussion}

Prepubertal children are approximately $30 \%$ more sensitive to insulin compared to individuals at puberty (Bloch et al. 1987; Amiel et al. 1986). Insulin resistance increases immediately at the onset of puberty (Tanner stage T2), but decreases to near prepubertal levels at Tanner stage T5 (Moran et al. 1999). In the present study, we demonstrated the existence of a peak of insulin resistance at the time of vaginal opening in C57BL/6 female mice, which depending on the animal occurred between the fourth and fifth weeks of life. Thus, like in humans, mice also develop this transient insulin resistance during puberty. There are several indicators of sexual maturation frequently used in female mice, including vaginal opening, first estrous, and regular estrous cyclicity (Nelson et al. 1990; Bohlen et al. 2016). Since vaginal opening is the first well-characterized temporal marker of pubertal development in female rodents, the insulin resistance in female mice peaks at the beginning of the puberty.

In contrast to females, no insulin resistance during puberty was identified in male mice. Several possibil- 


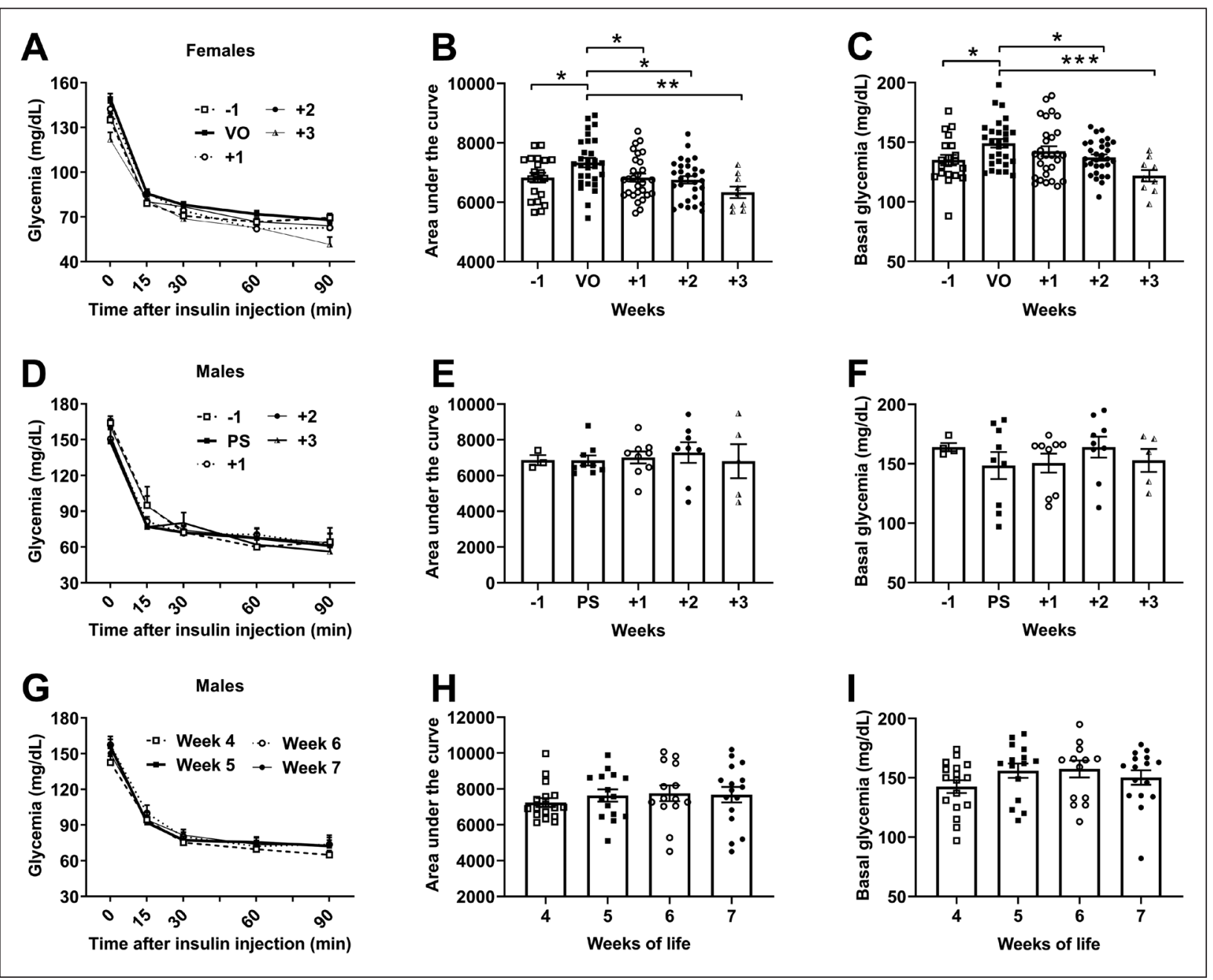

Figure 1. Female mice, but not males, display a transient insulin resistance during puberty. (A) Blood glucose levels during the insulin tolerance tests (ITT) in female mice (n=32). (B) Area under the curve (AUC) of the ITT in female mice. (C) Basal glycemia in female mice. (D) Blood glucose levels during the ITT in male mice $(n=9)$ according to the sexual maturation stage. (E) AUC of the ITT in male mice. (F) Basal glycemia in male mice. $(\mathbf{G})$ Blood glucose levels during the ITT in male mice $(\mathrm{n}=18)$ according to the age. (H) AUC of the ITT in male mice. (I) Basal glycemia in male mice. ${ }^{\star} \mathrm{p}<0.05,{ }^{* *} \mathrm{p}<0.01,{ }^{* * *} \mathrm{p}<0.001$. Abbreviations: PS - preputial separation; $\mathrm{VO}$ - vaginal opening.

ities can explain this sex difference. Previous studies have shown that girls are more insulin resistant than boys at all Tanner stages (Moran et al. 1999). To our best knowledge, there is no information in rodents about a possible sex dimorphism in the insulin resistance during puberty. However, when the area under the curve is compared between females and males at the time of VO and PS, respectively, female mice showed values $7 \%$ higher than males, although this difference does not reach statistical significance $(\mathrm{p}=0.1365)$. It is possible that the method used in our study to evaluate the insulin sensitivity may not be sensitive enough to detect variations in the pubertal male mice insulin resistance. Instead of performing
ITT, glucose tolerance could been evaluated. However, insulin resistance during puberty can be compensated by increases in glucose-stimulated insulin secretion, as previously shown in humans (Bloch et al. 1987; Hannon et al. 2006). Thus, glucose tolerance tests were probably unable to detect pubertal changes in the insulin resistance. The gold-standard method to measure insulin sensitivity is the hyperinsulinemiceuglycemic clamp (Furigo et al. 2019). However, this method is extremely challenging in very young mice and it would not allow the same animal to be tested at various moments during puberty. Another possibility how to explain the sex difference in the insulin resistance is that the timing of sexual maturation in 
male mice may be less defined than in females. Thus, the potential development of insulin resistance may not been able to be detected in a specific time point in males.

In summary, our findings demonstrate that the insulin resistance at puberty can also be observed in female mice. Thus, our temporal characterization can be used as an important reference for future studies that aim to study glucose homeostasis during puberty in rodents. A better understanding of the mechanisms related to transient insulin resistance can help in the study of the pathophysiology of diabetes mellitus, as well as contribute to the treatment of endocrine disorders that affect children and adolescents.

\section{Acknowledgement}

This study was funded by Fundacao de Amparo a Pesquisa do Estado de Sao Paulo (FAPESP/ Brazil; Grant numbers: $2017 / 02983-2$ to J.D. and 2020/10102-9 to M.R.T.) and Conselho Nacional de Desenvolvimento Cientifico e Tecnologico (CNPq/ Brazil; grant number: 160186/2015-3 to P.D.S.T.). J.D. is an investigator of the CNPq.

\section{References}

Amiel SA, Sherwin RS, Simonson DC, Lauritano AA, Tamborlane WV. Impaired insulin action in puberty. A contributing factor to poor glycemic control in adolescents with diabetes. N Engl J Med 315, 215-219, 1986.

Bloch CA, Clemons P, Sperling MA. Puberty decreases insulin sensitivity. J Pediatr 110, 481-487, 1987.

Bohlen TM, Silveira MA, Zampieri TT, Frazao R, Donato J, Jr. Fatness rather than leptin sensitivity determines the timing of puberty in female mice. Mol Cell Endocrinol 423, 11-21, 2016.

Furigo IC, de Souza GO, Teixeira PDS, Guadagnini D, Frazao R, List EO, Kopchick JJ, Prada PO, Donato J, Jr. Growth hormone enhances the recovery of hypoglycemia via ventromedial hypothalamic neurons. FASEB J 33, 11909-11924, 2019.

Hannon TS, Janosky J, Arslanian SA. Longitudinal study of physiologic insulin resistance and metabolic changes of puberty. Pediatr Res 60, 759-763, 2006.

Moran A, Jacobs DR, Jr., Steinberger J, Hong CP, Prineas R, Luepker R, Sinaiko AR. Insulin resistance during puberty: results from clamp studies in 357 children. Diabetes 48, 2039-2044, 1999.

Moran A, Jacobs DR, Jr., Steinberger J, Cohen P, Hong CP, Prineas R, Sinaiko AR. Association between the insulin resistance of puberty and the insulin-like growth factor-I/growth hormone axis. J Clin Endocrinol Metab 87, 4817-4820, 2002.

Nelson JF, Karelus K, Felicio LS, Johnson TE. Genetic influences on the timing of puberty in mice. Biol Reprod 42, 649-655, 1990.

Rizza RA, Mandarino LJ, Gerich JE. Effects of growth hormone on insulin action in man. Mechanisms of insulin resistance, impaired suppression of glucose production, and impaired stimulation of glucose utilization. Diabetes 31, 663-669, 1982.

Veldhuis JD, Roemmich JN, Richmond EJ, Bowers CY. Somatotropic and gonadotropic axes linkages in infancy, childhood, and the puberty-adult transition. Endocr Rev 27, 101-140, 2006. 